\title{
A enfermagem enQuanto disciplina, profissão e trabalho
}

\author{
Nursing as discipline, profession, and labour \\ La enfermería como disciplina, profesión y trabajo
}

\section{Denise Pires}

'Universidade Federal de Santa Catarina. Programa de Pós-Graduação em Enfermagem. Florianópolis, SC

Submissão: 12/13/2008

Aprovação: $31 / 08 / 2009$

\section{RESUMO}

Ensaio com objetivo de articular aspectos teórico-conceituais de profissão, disciplina e trabalho contribuindo para a reflexão acerca do saber disciplinar e da prática profissional de enfermagem exercida no contexto do trabalho coletivo em saúde. Resgata conceitos da teoria sociológica e da epistemologia para analisar a enfermagem no cenário da ciência, da sociologia das profissões e da teorização sobre processo de trabalho em saúde. Argumenta Que a enfermagem tem atributos de uma profissão e de uma disciplina cientíica, e oue os limites da prática precisam ser contextualizados histórica e socialmente. Conclui Que a enfermagem, enQuanto pratica social e disciplina, enfrenta desafios científicos e políticos demandando um processo permanente de construção.

Descritores: Enfermagem; Trabalho; Conhecimento; Educação em enfermagem.

\section{ABSTRACT}

The objective of this essay is to articulate theoretical-conceptual aspects of nursing as a profession, a scientific discipline, and labour contributing to reflection concerning nursing knowledge and professional practice exercised in the context of collective work in health care. It reviews concepts from sociological theory and epistemology in order to analyze nursing in the context of scientific community, and the sociology of professions, and the work process theories in health care. This paper argues that nursing has the attributes of a profession as well as a scientific discipline, and that the limits of nursing practice need to be historically and socially contextualized. It concludes that as a social practice and discipline, nursing faces scientific and political challenges which demand a permanent process of construction.

Descriptors: Nursing; Work; Knowledge; Education, nursing.

\section{RESUMEN}

El objetivo del presente ensayo es articular aspectos teórico-conceptuales de la enfermería como profesión, disciplina y trabajo, contribuyendo para la reflexión acerca del saber disciplinar y de la práctica profesional de la enfermería ejercida en el contexto del trabajo colectivo en salud. Rescata conceptos de la teoría sociológica y de la epistemología para analizar la enfermería en el ámbito de la ciencia, de la sociología de las profesiones y de la teoría sobre el proceso del trabajo en salud. Argumenta que la enfermería tiene atributos de una profesión y de una disciplina científica, y que los límites de la práctica deben ser contextualizados histórica y socialmente. Concluye que la enfermería como práctica social y disciplina, enfrenta desafíos científicos y políticos Que exigen un proceso permanente de construcción. Descriptores: Enfermería; Trabajo; Conocimiento; Educación en enfermería. 


\section{INTRODUÇÃO}

Considerando-se as múltiplas possibilidades de abordar um tema tão complexo e debatido, optou-se por um ensaio contextualizado histórica e socialmente neste início do século XXI, buscando uma nova síntese a partir da releitura de teses significativas pelo seu vigor teóricopolítico e epistemológico. Tem como objetivo articular aspectos teóricoconceituais de profissão, disciplina e trabalho com vistas a fundamentar a reflexão acerca do saber disciplinar e da prática profissional de enfermagem exercida no contexto do trabalho coletivo em saúde.

O processo metodológico de construção do texto partiu da teoria sociológica e da epistemologia destacando conceitos pertinentes para analisar a enfermagem no cenário da ciência, dos postulados da sociologia das profissões, e da teorização sobre processo de trabalho em saúde. A análise conclui-se com uma síntese que articula as três categorias teóricas mencionadas buscando contribuir com o debate acerca da realidade e desafios atuais da profissão de enfermagem.

\section{PROFISSÃO - CONSIDERAÇÕES TEÓRICAS}

Trabalho profissional, diz respeito a trabalhos especializados e reconhecidos socialmente como necessários para a realização de determinadas atividades. O conceito de profissão origina-se das características do trabalho do tipo artesanal desenvolvido nas guildas, ou corporações de artífices da Idade Média, Que se constituíam em unidades de produção, de capacitação para o ofício e de comercialização dos produtos. Nestas, apesar de existir divisão do trabalho, hierarQuia e atividades de coordenação e gerenciamento do processo de produção, os produtores eram donos dos instrumentos, tinham controle sobre o processo, o produto e o ritmo do trabalho, assim como sobre a produção e reprodução dos conhecimentos necessários ao seu trabalho ${ }^{(1-3)}$.

Segundo Machado ${ }^{(4)}$, resgatando a produção da Sociologia das Profissões, as características de uma profissão são: domínio de um conjunto de conhecimentos esotéricos adquiridos por um longo processo de formação; oferecimento de serviços especializados ao público; ser desenvolvida por indivíduos com vocação e regidos por um código de ética; a existência de regras para controle do exercício profissional elaboradas pelo grupo através de entidades Que os representem na sociedade; desenvolvimento da atividade em tempo integral, sobrevivendo desta remuneração; e gozar de autonomia profissional. Como melhores exemplos de profissão são apontados: medicina, engenharia, advocacia, cléricos e professores universitários.

Considerando-se esse cenário teórico, em uma perspectiva crítica, algumas das características apontadas são relevantes para definir "profissão". No entanto, é preciso analisar o significado destas características no contexto, e complexidade, das formas de organização do trabalho coletivo introduzidas pelo modo capitalista de produção, com o parcelamento de tarefas e a gerência científica e sua influência nos diversos setores da economia e, também, na saúde. Assim, pode-se afirmar Que "profissão" designa a Qualificação de um grupo de trabalhadores especializados na realização de determinadas atividades, os Quais dominam os conhecimentos Que fundamentam a sua realização. Os profissionais controlam a produção e reprodução dos conhecimentos necessários ao seu trabalho, através do ensino e da pesquisa. Os membros da profissão estabelecem regras para o exercício profissional, fixadas em lei e/ ou compartilhadas pelo grupo e legitimadas pela sociedade em Que vivem. Organizam-se em entidades do tipo associativo com vistas a garantir o respeito às regras estabelecidas, buscar o aprimoramento profissional e desenvolver medidas de defesa do grupo $^{(5-6)}$. No Que diz respeito ao "controle sobre o processo de produção" e a "autonomia profissional", é preciso considerar a influência do trabalho coletivo da produção capitalista, nas práticas profissionais institucionalizadas.

Analisando a enfermagem como uma profissão da saúde, dois aspectos têm sido apontados como frágeis: a autonomia profissional e o reconhecimento da utilidade social deste trabalho profissional e do domínio de um campo específico/próprio de conhecimentos.

\section{A ENFERMAGEM ENQUANTO PROFISSÃO DA SAÚDE E A UTILIDADE SOCIAL DE SEU TRABALHO}

Em relação à utilidade social do trabalho da enfermagem, apesar de não haver consenso em relação à natureza do cuidado de enfermagem, há consenso no Que diz respeito à estreita relação entre cuidado humano e o trabalho da enfermagem. A literatura é farta em registros da importância essencial do cuidado na sobrevivência das espécies, na promoção da vida e na preservação do planeta. Da geração da vida à sua manutenção e finitude é preciso cuidado ${ }^{(5-9)}$. No entanto, na sociedade atual, fortemente dependente de tecnologias materiais, influenciada pela comunicação global, centrada no consumo, nos valores mercantis e na biomedicina, valores como solidariedade, direito universal a vida digna e ao cuidado não são prioridade, dificultando a valorização de práticas como a da enfermagem.

A Enfermagem é uma profissão de saúde reconhecida desde a segunda metade do século XIX, Quando Florence Nightingale acrescenta atributos a um campo de atividades de cuidado à saúde desenvolvidas, milenarmente, por indivíduos ou grupos com diferentes Qualificações e em diferentes cenários. Com Florence, o cuidado ganha especificidade no conjunto da divisão do trabalho social, é reconhecido como um campo de atividades especializadas e necessárias/úteis para a sociedade e Que, para o seu exercício, requer uma formação especial e a produção de conhecimentos Que fundamentem o agir profissional.

A legalização da profissão de enfermagem em diversos países e o grande contingente numérico destes profissionais também demonstram o reconhecimento social da profissão. No Brasil, segundo o Conselho Nacional de Saúde, a enfermagem é uma das 16 profissões de saúde, seu exercício profissional está regulamentado pela Lei 7.498/1986 e segundo dados dos últimos cinco anos, do Ministério da Trabalho e Emprego, representa cerca de $60 \%$ do conjunto das profissões de saúde ${ }^{(10)}$. É a profissão Que está presente em todas as instituições assistenciais, sendo Que na rede hospitalar está presente nas 24 horas de todos os 365 dias do ano. Estes dados, por si só, já demonstram que a Qualidade das ações de enfermagem interfere, diretamente, na Qualidade da assistência em saúde.

Considerando-se os atributos de profissão, podemos afirmar Que a Enfermagem é uma profissão desenvolvida por um grupo de trabalhadores Qualificados e especializados para a realização de atividades socialmente necessárias. Conta com entidades Que a 
representam no conjunto da sociedade e Que formulam regras para o exercício profissional, além de dispor de um código de ética Que orienta o comportamento de seus agentes em bases moralmente aceitáveis, seja na relação com os sujeitos cuidados, seja na relação com os pares.

Ainda em relação aos atributos de uma profissão, domina um campo de conhecimentos Que lhe dá competência para cuidar das pessoas, em todo o seu processo de viver, Esse processo de cuidar tem três dimensões básicas: a) Cuidar de indivíduos e grupos, da concepção à morte. b) Educar e pesquisar Que envolve o educar intrínseco ao processo de cuidar; a educação permanente no trabalho; a formação de novos profissionais e a produção de conhecimentos que subsidiem o processo de cuidar. c) A dimensão administrativo-gerencial de coordenação do trabalho coletivo da enfermagem, de administração do espaço assistencial, de participação no gerenciamento da assistência de saúde e no

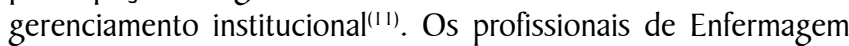
dominam os conhecimentos Que fundamentam as suas atividades $\mathrm{e}$ controlam a produção e reprodução dos conhecimentos necessários ao seu trabalho, através do ensino e da pesquisa. Neste sentido destaca-se a contribuição da formação de Mestres e Doutores em Enfermagem em muitos países ${ }^{(12)}$, para a produção de conhecimentos sobre o processo de viver humano, o cuidado em saúde, as práticas assistenciais fortalecendo a Enfermagem enQuanto disciplina do conhecimento científico.

\section{ENFERMAGEM ENQUANTO DISCIPLINA CIENTÍFICA}

Em relação ao domínio de um campo específico de conhecimentos, dialogando com filosofia da ciência, encontra-se Que uma disciplina científica "é uma categoria organizadora dentro do conhecimento científico; ela institui a divisão e a especialização do trabalho e responde à diversidade das áreas Que as ciências abrangem"(13). A disciplina constitui-se em "uma estrutura mental, consciente ou não, Que serve para classificar o mundo e poder abordá-lo"(14). É culturalmente delimitada porQue sempre parte de idéias prévias e conhecimentos práticos do cotidiano a respeito de determinada Questão ou do tema. É, também, historicamente delimitada ou seja algumas idéias e Questões somente são colocadas em determinados momentos históricos. Por exemplo, só foi possível falar de psicologia a partir de certa concepção de ser humano, de indivíduo, e a diferenciação do ser humano, como indivíduo e como social, permitiu o nascimento da psicologia e da sociologia ${ }^{(14)}$. Assim, também, somente a partir de Florence Nightingale a idéia de cuidado passa a ser discutida como objeto de estudo do Que viria a constituirse a enfermagem, embora as idéias e formulações sobre cuidado sejam muito anteriores, como mencionam diversos autores ${ }^{(8-15)}$. A enfermagem, enquanto um trabalho do campo da saúde, cuida de seres humanos, em suas múltiplas dimensões. Esse cuidado de enfermagem constitui-se no objeto de estudo da disciplina enfermagem.

Segundo Fourez ${ }^{(14)}$, "em torno e na base de cada disciplina científica, existe um certo número de regras, princípios, estruturas mentais, instrumentos, normas culturais e/ou práticas, Que organizam o mundo antes de seu estudo mais aprofundado". A classificação delimita o Que pertence a disciplina em relação a outros campos do conhecimento. Faz um corte, ou seja, separa os fenômenos físicos dos químicos, o Que é da psicologia (perspectiva do indivíduo) e o que é da sociologia (perspectiva da sociedade), o Que é da medicina (o diagnóstico e a intervenção sobre a doença) e o que é da enfermagem (a busca do bem estar dos seres humanos, seja dos Que estão doentes, seja no sentido de promover o bem estar e a saúde). "Essa separação, essa construção do objeto pela comunidade científica, é o que Bachelard chama de 'rupturas epistemológicas"(15,16).

Ainda, considerando as formulações de Fourez ${ }^{(14)}$, o objeto de uma disciplina não existe antes da sua existência, ele é construído por ela e pode variar na sua evolução. "Uma disciplina não é definida pelo objeto que estuda, mas é ela Que o determina". Nesta perspectiva, o cuidado de enfermagem pode ser considerado como um objeto em debate e construção no próprio processo de estruturação da disciplina enfermagem. A construção, pela comunidade científica, do objeto de uma disciplina, estabelece a ruptura epistemológica, no sentido de Bachelard ${ }^{(16)}$, a Qual dá estatuto a um saber determinado. E, esse estabelecimento do objeto da disciplina é o que lhe dá a "objetividade" de uma disciplina científica. Na base da prática científica existem ações humanas e não um objeto dado, predeterminado ${ }^{(14)}$.

Refletindo sobre a medicina como paradigma de disciplina científica, o mesmo autor ${ }^{(18)}$ registra que a medicina ao estruturar o seu paradigma disciplinar no estudo das doenças, na "extração do mal" e na "cura do doente", prioriza o "diagnóstico sobre o tratamento", "a cura sobre a higiene", "o corpo sobre a psicologia", "as especializações sobre a medicina geral", "a cura sobre o bem viver". Se o paradigma construído na saúde priorizasse o outro lado da dualidade mencionada, as práticas nesta área não se concentrariam sobre um indivíduo 'abstrato' [...] separado da realidade afetiva e social em Que vive, mas sobre uma pessoa integrada à sua vizinhança, ao seu meio de trabalho, à sua região e ao universo. A profissão de enfermeiro seria mais valorizada, pois considerar-se-ia importante Que uma pessoa fosse bem acolhida, reconfortada e cuidada pessoalmente, a ponto de poder se instruir com a sua doença e tirar dela novas forças. Toda uma série de conhecimentos surgiria, tão eficazes talvez Quanto os Que conhecemos hoje $\mathrm{e}^{(14)}$.

A idéia de paradigma origina-se de Thomas Kuhn, no sentido de "um conjunto de regras e de representações mentais e culturais ligadas ao surgimento de uma disciplina científica"(14:17). Khun introduziu, também, a idéia de "ciência normal", ou seja, o trabalho científico é desenvolvido seguindo regras acordadas pela comunidade científica, e Quando o âmbito paradigmático de uma disciplina é Questionado, com múltiplas contestações a suas regras e estatuto se estabelece uma "revolução científica", Que gerará novos padrões de regularidade para a produção científica, assim como novas disciplinas.

A constituição de QualQuer disciplina científica envolve um período pré-paradigmático, mais ou menos longo, no Qual as práticas da disciplina ainda não estão bem definidas. Neste período, ainda não existem formações universitárias precisas para formar especialistas na disciplina ${ }^{(14)}$

O processo de construção da disciplina Enfermagem nasce com a necessidade social de Qualificar o cuidado de enfermagem para amplos grupos populacionais, o Que motivou os estudos de Florence Nightingale, na Inglaterra do século XIX"(18,19). Para a autora, cabe 
a enfermagem prover um "ambiente propício para Que a natureza pudesse agir, fortalecendo o poder vital das pessoas", assim como buscou "demonstrar os efeitos dos ambientes de cuidado na promoção da saúde das pessoas"(7,18). A disciplina vai ganhando corpo com a sistematização das técnicas de enfermagem e dos princípios científicos Que as fundamentam, e com a construção das teorias de enfermagem a partir dos anos 50 do século passado ${ }^{(20)}$. As teorias de enfermagem têm buscado definir cuidado, cuidado de enfermagem e o processo de cuidar, no entanto, não há consenso em relação a definição de cuidado, de seus componentes, nem em relação ao processo de cuidar $^{(21)}$. Estas formulações e debates contribuem para a estruturação da enfermagem enQuanto disciplina do campo da saúde Que assume o cuidado como seu objeto epistemológico ${ }^{(22)}$.

Já o período paradigmático diz respeito à disciplina estabelecida, com relativa estabilidade de objeto e técnicas, realizando pesquisas e produzindo conhecimentos dentro de um padrão aceitável pela comunidade científica da época - é o funcionamento da ciência normal khuniana. A disciplina também pode se esgotar perdendo todo o contato com as Questões externas, não respondendo a Questões da prática cotidiana, iniciando assim a sua desestruturação.

Considerando-se a definição do objeto, técnicas de investigação e teorias, pode-se dizer Que a disciplina Enfermagem aproxima-se do patamar paradigmático ou da "ciência normal". No entanto, é importante considerar que a construção de uma disciplina científica, assim como a organização de uma profissão, não se dá em um cenário neutro, sem disputa de poder e de interesses econômicos e políticos. Na sociedade atual, estruturada sob os padrões do capitalismo, organizada para a competição e o mercado, aproximase mais dos interesses das indústrias de produção de medicamentos e equipamentos hospitalares, e dos padrões da ciência positiva Que fundamenta a biomedicina, do que de práticas de cuidado Que se aproximam dos ideais de igualdade, de justiça social, de bem estar e de felicidade.

\section{QUE CUIDADO É CUIDADO DE ENFERMAGEM?}

Ayres $^{(15)}$ diz que o cuidado pode ser analisado como categoria ontológica e genealógica. Na perspectiva ontológica, é entendido como essência do ser humano, cuja identidade é construída no processo de viver, permeada de interações, e tem uma plasticidade de matéria em constante transformação. Tem um potencial criador, de conceber e construir projetos. "Que estranho personagem é o cuidado! Ele não é o Ser, mas sem ele não há ser; ele não é a matéria nem o espírito, mas sem ele a matéria não está para o espírito e nem o espírito para matéria; ele é uma dádiva do tempo, mas o tempo deve a ele a existência"(15).

O cuidado como categoria genealógica é construído a partir de Foucault ${ }^{(23)}$, no entendimento da arte existencial do cuidado de si, através do Qual o ser humano cuida do seu corpo e de sua alma, construindo por meio desta trama a sua felicidade. Ao ser humano foi confiado o cuidado de si, sendo que a medicina, historicamente, tem formulado idéias e prescrições a respeito do conjunto de atividades implicadas no cuidado de si como: exercícios, dietas, atividade sexual, meditações, leituras, dentre outros ${ }^{(15)}$.

O cuidar nas práticas de saúde busca desenvolver atitudes e espaços de genuíno encontro intersubjetivo, de exercício de sabedoria prática para saúde apoiado em tecnologia, mas sem resumir-se a elas ${ }^{(15)}$.

A história da humanidade mostra, desde os seus primórdios, Que os seres humanos precisam de cuidado para sobreviver, para viver com saúde, felicidade e bem estar, e para curar-se em situações de doenças.

O cuidado tem sido tema de estudo de filósofos, de historiadores e de antropólogos, mas é a Enfermagem a profissão do cuidado, e a Que mais tem produzido conhecimentos para fundamentar as diversas dimensões do cuidado.

No que diz respeito à saúde, o processo de cuidar requer muito mais Que tecnologia para produzir medicamentos, equipamentos médico-hospitalares e diagnósticos precisos. É muito mais Que cuidar de uma "parte do corpo Que não está funcionado bem, ou Que foi lesada" como orienta o paradigma da biomedicina. É preciso produzir conhecimentos para cuidar de seres humanos como individualidades complexas, na dimensão familiar e eneuanto parte de grupos sociais e de sociedades históricas ${ }^{(1)}$.

Morse et $\mathrm{al}^{(21)}$ registram Que o cuidado tem sido descrito pelas teoristas de enfermagem como o "core" ou conteúdo central para a enfermagem, e que não há dúvida de Que, como um conceito, "o cuidado" tem desenvolvido importante influência sobre a pesQuisa, a educação e filosofia da enfermagem. Qual a natureza do cuidado? Qual a natureza do cuidado de enfermagem? Todo cuidado humano é de enfermagem? Outros profissionais de saúde, como por exemplo, psicólogos e assistentes sociais, também cuidam? O Que significa cuidar? Qual o significado do cuidado para os profissionais de enfermagem e para as pessoas Que são cuidadas pela enfermagem? As autoras mencionam cinco categorias de cuidado: cuidado como essência humana, como imperativo moral, como um efeito, como relação interpessoal e como uma intervenção terapêutica. "Ninguém vive sem cuidado, ninguém é curado sem cuidado e ninguém é atendido em um serviço de saúde de média complexidade sem Que a enfermagem tenha direta ou indiretamente influência no resultado da assistência recebida"(11,24).

Neste cenário, destacam-se duas considerações sobre o cuidado humano. Primeiro, o cuidado pode ser realizado fora do âmbito do trabalho profissional em saúde e sem a fundamentação de uma disciplina científica, como é o caso de múltiplas ações terapêuticas Que são realizadas no subsistema informal (famílias, relações pessoais, grupos de auto-ajuda) ou popular (diversos curadores não profissionais) como é bem documentado pela antropologia da saúde ${ }^{(25-26)}$. Segundo, a demanda por cuidado pode requerer um trabalho profissional, seja na perspectiva da promoção da saúde e da vida, seja na perspectiva terapêutica, no âmbito individual ou coletivo, e nos diversos tipos de instituições de saúde. Neste campo, não é só a enfermagem Que cuida. O trabalho de outros profissionais de saúde pode ter uma dimensão cuidadora, no entanto, a profissão Que coloca o cuidado como objeto epistemológico e como core de seu agir profissional é a enfermagem.

O cuidar em enfermagem, em termos genéricos, tem o sentido de promover a vida, o potencial vital, o bem estar dos seres humanos na sua individualidade, complexidade e integralidade. Envolve um encontro interpessoal com objetivo terapêutico, de conforto, de cura Quando possível e, também, de preparo para a morte Quando inevitável. No entanto, a prática concreta da enfermagem nos espaços institucionais muitas vezes não corresponde a essa perspectiva, necessitando uma análise sob olhar de outra categoria teórica - a categoria trabalho. 


\section{A ENFERMAGEM ENQUANTO TRABALHO EM SAÚDE - O CONTEXTO DA AUTONOMIA PROFISSIONAL}

O trabalho da enfermagem ocorre em sociedades históricas, no contexto do trabalho em saúde e do paradigma hegemônico de ciência. Neste cenário interage com outros profissionais de saúde e é influenciada pelas demandas e constrangimentos institucionais.

Os diversos profissionais de saúde, apesar de suas especificidades de conhecimentos e de prática, ao exercerem o seu trabalho no âmbito institucional, majoritariamente, o desenvolvem como parte de um trabalho coletivo. Esse trabalho envolve, basicamente, a avaliação de um indivíduo ou grupo, seguida da indicação e/ou realização de uma conduta terapêutica. $\mathrm{O}$ trabalho assistencial em saúde é gerado por necessidades/carências relacionadas à saúde e é dirigido a um objeto compartilhado - seres humanos Que necessitam deste trabalho profissional e Que são totalidades complexas e multidimensionais. O resultado do trabalho em saúde não é um produto material. O produto é indissociável do processo de produção, é a própria assistência Que é produzida e consumida simultaneamente ${ }^{(6,22)}$.

Tanto no setor público Quanto no setor privado, a assistência profissional em saúde é realizada, cotidianamente, no âmbito hospitalar e ambulatorial por múltiplas profissões de saúde, dependendo do país e do período histórico. Múltiplos arranjos e reQuisitos de profissionalização e organização são possíveis. Cada grupo profissional inclui trabalhadores com formação de nível superior podendo, também, incluir trabalhadores com formação técnica de nível médio. Além dos profissionais envolvidos com a assistência de saúde, em si, existe outro grupo de trabalhadores, com diversas Qualificações, Que desenvolvem atividades Que não são específicas do trabalho em saúde, mas Que são fundamentais para Que a assistência institucional se realize, como o pessoal da limpeza, escriturários, segurança e outros ${ }^{(6)}$.

O trabalho em saúde e enfermagem envolve uma relação entre sujeitos. O cuidador - sua subjetividade, história, direitos, necessidades, relações com os demais participantes do trabalho coletivo, concepção cultural-profissional de saúde; e o sujeito cuidado - suas necessidades e concepções culturais de saúde. Estas expectativas e interesses podem aproximar-se, potencializando a perspectiva do cuidado "de si e do outro" ou distanciar-se gerando conflitos.

A enfermagem, considerando-se a sua característica intrínseca de cuidar de seres humanos, tem potencial para uma maior aproximação com as múltiplas dimensões do objeto de trabalho em saúde. Neste sentido, precisa alimentar-se de diversas disciplinas do campo das humanidades, além daquelas básicas e tradicionais da "ciência normal" em saúde (biologia, fisiologia e outras). No entanto, majoritariamente, a prática assistencial, a produção de conhecimentos e a formação profissional têm sido fortemente influenciadas pela ciência positivista e pelos padrões da biomedicina, de modo que, no âmbito do trabalho coletivo em saúde, a enfermagem tem tido pouca força para se contrapor ou diferenciar-se do modelo hegemônico.

O debate sobre autonomia profissional precisa considerar o cenário político-institucional e organizativo no Qual ocorre o trabalho em saúde. Assim, ao analisarmos o processo e organização do trabalho dos profissionais envolvidos diretamente no "ato assistencial em saúde” percebe-se, simultaneamente, características do trabalho profissional e do gerenciamento e trabalho coletivo da produção capitalista. No âmbito do trabalho coletivo, os diferentes grupos de trabalhadores com formações profissionais distintas, desenvolvem parte do ato assistencial, com maior ou menor autonomia técnica e maior ou menor entendimento a respeito de seu objeto de trabalho e das necessidades que demandaram a assistência de saúde. O entendimento sobre características e necessidades do objeto de trabalho, bem como o maior ou menor domínio sobre o processo de trabalho, tem conseQüências na capacidade dos profissionais intervirem, mais ou menos criativamente, na definição de suas ações, com vistas a atingir as finalidades do seu trabalho. As normas institucionais estabelecem os papéis de cada grupo profissional e a coordenação do trabalho coletivo. Na prática cotidiana, os profissionais de saúde exercem seu trabalho com certa autonomia técnica, "liberdade de julgamento e tomada de decisão frente às necessidades de saúde dos usuários”(27). Essa característica ocorre concomitante as "diferenças técnicas especializadas e a desigualdade de valor atribuído a esses distintos trabalhos"(28). A hierarouia de trabalhos e de saberes se manifesta nas relações de trabalho resultando em tensões entre os diversos agentes, com conflitos explícitos ou não.

Internamente a algumas profissões da saúde, como por exemplo, enfermagem, fisioterapia e nutrição, o trabalho é desenvolvido por trabalhadores com grau de escolaridade diferenciado. A coordenação do trabalho, dentro do grupo profissional, é exercida pelos profissionais de nível superior Que, majoritariamente, delegam atividades parcelares aos trabalhadores de nível médio. Essa forma de organização e divisão do trabalho reproduz a fragmentação taylorista, mas é possível encontrar-se diferenciações, com maior ou menor aproximação com um trabalho cooperativo, mais criativo e menos alienado.

A história da organização das profissões de saúde mostra o processo de institucionalização da medicina como detentora legal do saber em saúde, e elemento central do ato assistencial. Apesar do controle médico sobre as demais profissões da saúde, em termos de formação e de regras para o exercício profissional, ter se relativizado com a organização independente de diversos grupos profissionais em saúde, especialmente a partir do século XIX, e do século XX, os médicos mantém, até hoje, certa hegemonia no setor. Podem exercer a globalidade do ato assistencial mas aos demais profissionais de saúde é vedado o exercício de atividades como o diagnóstico clínicocirúrgico, a decisão sobre a terapêutica e sobre a internação e alta hospitalar, mantidos como privativos dos médicos ${ }^{(5-6)}$.

No entanto, apesar do trabalho coletivo institucional estar influenciado pelas políticas de saúde, pela história, pelos constrangimentos institucionais, pelas legislações profissionais e pela lógica de organização do trabalho coletivo, a gerência da instituição não consegue desenhar um projeto assistencial rígido antes de sua implementação de modo a submeter o trabalho da equipe multiprofissional. A gerência não consegue dominar a concepção e nem controlar rigidamente os processos de execução do trabalho, há um espaço de autonomia técnica o Que se aproxima das características de um trabalho profissional.

\section{OS DESAFIOS ATUAIS, A GUISA DAS CONSIDERAÇÕES FINAIS}

Articulando as reflexões sobre trabalho, disciplina e profissão conclui-se Que a Enfermagem é uma profissão da saúde, uma 
disciplina do campo da ciência que estuda o cuidado humano e Que se materializa como trabalho exercido em sociedades históricas. Os cenários político-institucionais e o paradigma hegemônico de ciência delimitam as condições de trabalho, as possibilidades do exercício da autonomia e de aproximação do cuidar de seres humanos considerando sua individualidade, complexidade e possibilidades concretas de viver saudável.

A Enfermagem enQuanto disciplina do âmbito da ciência tem a responsabilidade de contribuir, permanentemente, com a produção de conhecimentos capazes de sustentar ações de cuidado culturalmente congruentes, tecnicamente competentes, moralmente aceitáveis e Que contribuam para preservação da vida em sua plenitude nas diversas situações do processo de viver humano. No entanto, essa produção tem desafios científicos e políticos, destacando-se os limites disciplinares para dar conta da complexidade da vida em sociedade.

Como profissão, é fundamental ter entidades fortes que a representem no âmbito da sociedade e Que formulem regras e parâmetros legais e éticos para o exercício profissional. Como um campo do trabalho em saúde precisa construir e defender um modelo de organização do trabalho Que considere o direito à saúde para o conjunto da população e o provimento de ações tecnicamente competentes e protetoras dos direitos dos usuários, assim como possibilite, a seus exercentes, a expressão da subjetividade e do prazer criativo no trabalho. É preciso considerar, ainda, os múltiplos sujeitos envolvidos no trabalho coletivo em saúde, os diferentes profissionais e as diferenças individuais e culturais Que se apresentam nas múltiplas e desafiantes situações cotidianas de trabalho.

\section{REFERÊNCIAS}

1. Braverman H. Trabalho e capital monopolista: a degradação do trabalho no século XX. Rio de Janeiro: Zahar; 1981 .

2. Marx K. O capital. São Paulo: Difel; 1982.

3. Pires D. Divisão Social do Trabalho. In: Escola Politécnica de Saúde Joąuim Venâncio, organizador. Dicionário da Educação Profissional em Saúde. Rio de Janeiro: FIOCRUZ; 2009. p. 125-30.

4. Machado MH, organizador. Profissões de saúde: uma abordagem sociológica. Rio de Janeiro: Fiocruz, 1995.

5. Pires D. Hegemonia médica na saúde e a enfermagem. São Paulo: Cortez; 1989.

6. Pires D. Reestruturação produtiva e trabalho em saúde no Brasil. São Paulo: AnnaBlume/CNTSS; 2008.

7. Neves EP. As dimensões do cuidar em enfermagem; concepções teórico-filosóficas. Rev Enferm Escola Anna Nery 2002; 6(I): 79-92.

8. Boff L. Saber cuidar: ética do humano, compaixão pela terra. Petrópolis:Vozes, 1999

9. Collière MF. Promover a vida: da prática de mulheres de virtude aos cuidados de enfermagem. Lisboa: Lidel; 1999.

10. Ministério do Trabalho e Emprego (BR). Relação Anual de Informações Sociais/RAIS, Brasília: Ministério do Trabaho; 2000.

11. Pires D, Kruse H, Silva E. A enfermagem e a produção do conhecimento. I Assoc Bras Enferm 2006; 14-5.

12. International Network for Doctoral Education in Nursing. Directory for International Doctoral Programs. [cited 2009 may 06]. Available at: http://www.umich.edu/ inden/programs/ index.htm

13. Morin E. A cabeça bem-feita: repensar a reforma, reformar o pensamento. Rio de Janeiro: Bertrand Brasil; 2000.

14. Fourez G. A construção das ciências: introdução à filosofia e a ética das ciências. São Paulo: UNESP; 1995.

15. Ayres JRCM. Cuidado e reconstrução das práticas de saúde. Interface 2003; 8(14): 73-92.

16. Bachelard G. O novo espírito científico. Lisboa: Textos Filosóficos Edições 70; 1996.

17. Kuhn T. A estrutura das revoluções científicas. São Paulo: Perspectiva; 2003.

18. Nightingale F. Notas sobre enfermagem. São Paulo/Ribeirão Preto: Cortez/ABEN-CEPEn; 1989.

19. Consejo Internacional de Enfermeras. Servir a la comunidad y garantizar la calidad: las enfermeras se comprometen a dispensar cuidados innovadores. Genebra: ICN; 2009.

20. Almeida MCP. O saber de enfermagem e sua dimensão prática. São Paulo: Cortez; 1986.

2I. Morse IM. Concepts of caring and caring as a concept. Adv Nurs Sci 1990; 13(1): 1-14.

22. Leopardi MT, Gelbke F, Ramos F. Cuidado: objeto de trabalho ou objeto epistemológico da enfermagem? Texto Contexto Enferm 2001; 10(1): 32-49.

23. Foucault M. História da sexualidade. Rio de Janeiro: Graal; 2002.

24. Leininger M. Culture Care Theory: A Major Contribution to Advance Transcultural Nursing Knowledge and Practices. I Transcult Nurs 2002; 13 (3): 189-92.

25. Kleinman A. Patients and healers in the context of culture. Berkley: University of Califórnia; 2009.

26. Helman CG. Cultura, saúde e doença. Porto Alegre: Artes Médicas; 2003.

27. Schraiber LB, Peduzzi M. Tendências e possibilidades da investigação de recursos humanos em saúde no Brasil. Educ Méd Salud 1993: 27:295-313.

28. Peduzzi M. Equipe multiprofissional de saúde: conceito e tipologia. Rev Saúde Pública 200 I; 35(1): 103-9. 